\title{
El tratamiento de la violencia en el fútbol por la prensa deportiva
}

\section{José Barrero Muñoz}

Profesor de Periodismo y Comunicación Audiovisual.

Universidad Europea de Madrid.

Resumen:

Los periodistas también tienen su protagonismo dentro de la violencia en el deporte. Desde múltiples organismos preocupa mucho y se ha señalado la necesidad de que los medios de comunicación cuiden sus conductas para no crear un ambiente violento. En este trabajo damos un exhaustivo repaso a las acciones de los periodistas deportivos que contribuyen a caldear el clima de violencia que se da concretamente en el fútbol, deporte más seguido en el país. Y todo, con especial atención al lenguaje bélico, militar y con tinte violento, que utilizan en los textos de las crónicas en los diarios deportivos.

Palabras clave:

Violencia - periodistas - medios de comunicación - crónicas - fútbol - lenguaje - retórica - influencia receptores.

\section{Abstract:}

Journalists are also main players with regard to violence in sports. Many organisms are worried about this issue and have pointed out the need for the mass media to take care of their own behaviour in order not to create a climate of violence. In this report, we exhaustively review those actions carried out by sports journalists that contribute to enhance a violent environment in soccer, the most popular sport in the country. We will pay special attention to those words that carry war-like, military and violent content and that are used throughout the text of chronicles in sports dailies.

Key words:

Violence - journalists - mass media - chronicles - soccer - language - rhetoric - influence - receptors. 


\section{Introducción}

La violencia es uno de los principales problemas de la sociedad en todos los órdenes, en todos los tiempos, en todos los lugares. Pero, es especialmente en occidente donde se están realizando estudios que intentan investigar para erradicarlo del ser humano, de la convivencia entre personas. Violencia terrorista, guerras, violencia callejera, doméstica, violencia de género, sexual, contra la naturaleza, violencia en el deporte... son algunos de los campos donde se pueden observar estas conductas. Y todos los análisis científicos que se hagan con el objetivo de acabar con la violencia en la vida humana deben ser bienvenidos ${ }^{1}$.

Entre todos los campos de investigación posible hemos seleccionado, por conocimiento profesional, la violencia en el deporte y más concretamente el fútbol. Este es el deporte con más seguidores en todo el mundo ${ }^{2}$ y donde se están dando muchísimos casos y los más graves de violencia.

Esta realidad se podría analizar también desde diferentes perspectivas. Por ejemplo, son distintos los protagonistas que participan en este espacio vital como los futbolistas, los entrenadores de los equipos, los dirigentes de los clubes, los árbitros, los espectadores y también los medios de comunicación.

Y es que se ha dicho mucho acerca de la participación de los medios de comunicación en la violencia que se da en nuestra sociedad. Tanto televisión, radio, prensa o Internet tienen su papel dentro de estos planteamientos, aunque cada uno contribuye de forma distinta y particular. Principalmente se achacan las conductas violentas a la televisión por su poder de atracción, de influencia y de formación de la personalidad; además de ser el medio más seguido. Se tiene presente en la mayoría de investigaciones que la violencia en televisión causa efectos que perjudican a los televidentes en general, pero sobre todo en los niños y adolescentes. Aun así, los demás medios también tienen su responsabilidad y un modo diferente de participar en esta cuestión.

Al respecto se han comentado distintas teorías ${ }^{3}$ sobre la influencia de los medios en la violencia real, principalmente procedentes de los teóricos del aprendizaje social. Algunos investigadores consideran que ver violencia tiene más posibilidades de violentar al ser humano que de pacificarle. Por tanto, nuestra investigación se centra en el papel o la responsabilidad que tienen los periodistas en la violencia

\footnotetext{
1 "He visto benevolencia, generosidad y altruismo en los lugares más oscuros... convencido de que entre todos continuaremos reduciendo el sufrimiento que la crueldad humana causa... la humanidad es esencialmente bondadosa”. Rojas Marcos, L. (1995: 13-14). Esto es algo que nos ayuda para continuar la investigación en todos los ambientes donde se desenvuelve y vive el ser humano.

2 “247 millones de personas juegan o están relacionadas con el fútbol”, encuesta mundial FIFA 2001.

${ }^{3}$ Clemente, M. y Vidal, M.A. (1996): Violencia y televisión, Madrid: Noesis.

4 "Es altamente dudoso que la visión de espectáculos violentos nos purifique y libere de nuestra pulsión violenta; lo más probable es que, por el contrario, incremente nuestras actitudes y comportamientos violentos”. Sanmartín, J. (2000: 105)
} 
en el deporte y más concretamente en el léxico violento que utilizan para transmitir sus crónicas de los partidos de fútbol.

\section{La violencia en el fútbol a través de los medios de comunicación}

La gran cuestión sobre nuestro estudio particular, que se plantean todos los investigadores, es si toda la violencia que se transmite a través de los medios de comunicación puede influir en el cambio de nuestras conductas y que se vuelvan más agresivas. Pero son múltiples las variables a tener en cuenta. Se sabe que hay mucha violencia en los medios, que estos cumplen un papel dentro de esta problemática y que se puede estudiar cuál es su parte en la cuestión (la violencia de los medios de comunicación, sus conductas que hacen que los receptores puedan ser violentos).

El problema para la investigación sobre los efectos de la violencia a través de los medios es que el analista no puede asegurar totalmente que el violento ha sido inducido e influido por los mismos medios de comunicación para llevar a cabo su acción agresiva. Quizás éste haya actuado así por otro motivo o por un cúmulo de circunstancias ${ }^{5}$. Por tanto, no se puede asegurar totalmente que la violencia en los medios de comunicación sea la causa de la violencia en el mundo real. Sí que parece haber un claro consenso en que la violencia en los medios puede estimular la agresión en la vida cotidiana.

Por otra parte, en la mayoría de estudios realizados se contempla el papel que protagonizan los demás agentes del deporte, pero no ha sido tratada a fondo la investigación sobre el protagonismo de los medios de comunicación dentro de la violencia en el fútbol ${ }^{6}$. Esto es lo que nos hemos propuesto con este análisis.

Desde todos los estamentos se ha constatado que los medios de comunicación cumplen un papel principal en la violencia que se da dentro del mundo del fútbol. En uno de los últimos grandes estudios que se han realizado sobre la violencia en el deporte, el Dictamen de la comisión especial de investigación de la violencia en espectáculos deportivos, con especial referencia al fútbol aprobado por el Pleno del Senado español en marzo de 1990, se entrevistó a personas relacionadas con todos los sectores que pudieran afectar a alguna de las cuestiones del tema a analizar: miembros de los clubes de fútbol

${ }^{5}$ Bandura señala que "el asunto de los efectos de los medios con frecuencia está mal planteado y se discute en términos de si dicha influencia actúa como la causa única del comportamiento. Dado que la conducta requiere la coexistencia de múltiples determinantes, la cuestión que se plantea es saber si la influencia de los medios actúa o no como un ingrediente importante dentro de las múltiples causas del comportamiento, no si es o no la causa única del mismo”. Bandura, A. (1987: 198)

6 "Los medios de comunicación social, radio, prensa y televisión, tienen una gran parte de culpa de la agresividad y violencia que ocurre en el deporte de hoy. Su influencia penetra en millones de hogares, de conciencias, imponiendo la regla de su información crítica. Los comentarios, en cualquier medio de comunicación, en la mayor parte de las veces son sumamente analizados, exagerándolos y poniéndose mucho énfasis y corazón, no contribuyendo con ello a calmar la pasión o la agresividad, y menos aún a promover el juego limpio". De Antón, J. y Pascual del Riquelme y Tejera, A. (1990: 128) 
(y baloncesto), del mundo de la justicia, de los Cuerpos de Seguridad del Estado, de organismos deportivos, de medios informativos e, incluso, los entonces Secretarios de Estado de Educación y de Deporte.

En la mayoría de las comparecencias de estos protagonistas se hizo referencia a los medios de comunicación como uno de los factores principales que promueven la violencia en el deporte, especialmente en el fútbol (ocupó el tercer lugar en la lista): "Otro gran factor que influye en la aparición de fenómenos violentos en los acontecimientos deportivos son los medios a través de sus periodistas deportivos" (De Antón y Pascual del Riquelme, 1990: 127).

Concretamente, estas fueron algunas de las declaraciones que se hicieron y que apuntaban como culpables a los medios de comunicación: exhibicionismo de la violencia en los medios, demasiada publicidad de estos actos y de sus actores, las declaraciones de los dirigentes y otros protagonistas de las que se hacen eco los medios y que se hacen públicas a través de ellos, las equivocaciones o "mala elaboración" de las noticias, el periodismo sensacionalista y promotor de violencia, el lenguaje bélico de los medios de comunicación social, la recreación de los medios en la violencia, las informaciones previas y posteriores a los partidos de fútbol, el "calentamiento del ambiente por los medios de comunicación", los comentarios y declaraciones de los periodistas, falta de neutralidad en los medios, entre otras muchas acusaciones.

De todas formas, como hemos señalado, resulta complicado saber hasta qué punto los medios pueden influir en las conductas de espectadores, jugadores, entrenadores o dirigentes futbolísticos, antes, durante o después de los partidos de fútbol. Por ejemplo, es difícil saber qué es lo que ha podido incitar a un espectador a lanzar una botella contra un jugador durante el encuentro de fútbol. Pero lo que sí está comentado por los estudiosos de la cuestión es que la mecha de la violencia se puede encender desde los medios de comunicación.

Entre estos aspectos con los que se puede crear un ambiente violento, nos detendremos en el léxico utilizado por los periodistas deportivos en las crónicas de los partidos de fútbol. Pese a que el lenguaje futbolístico tiene muchos vocablos tomados de las confrontaciones bélicas, en muchas ocasiones se abusa de palabras con tintes violentos, se utilizan numerosas metáforas bélicas o militares... De hecho, destacan términos procedentes de estos campos semánticos? ${ }^{7}$ También son muy frecuentes otras cons-

${ }^{7}$ Algunos de los ejemplos que apunta Gutiérrez son "campo de batalla, contienda, choque o duelo; pelea épica, guerra sin cuartel, guerra a muerte; la vanguardia o ataque, la ofensiva, la retaguardia o defensa, muralla o muro defensivo; enemigo o adversario; acoso, arremetida, asedio o carga; iniciar o romper las hostilidades, contraataque, pólvora mojada, bombarderos o cañoneros" son sólo algunos ejemplos de las expresiones que se pueden encontrar y que menciona el profesor Gutiérrez. Y su explicación es que "sea porque el deporte surge como canalización de la guerra, sea porque existe por mor del profesionalismo, una regresión hacia las formas de la milicia, sea porque la competición dota de matices pasionales la lucha entre equipos y genera un relato marcadamente épico, el hecho es que el lenguaje de la crónica de fútbol está impregnado con llamativa abundancia de un léxico que históricamente había pertenecido a la actividad bélica. En gran medida, la mayor parte de los términos de la milicia y de la guerra presentes en la crónica tiene una naturaleza metafórica”. (Gutiérrez, 1991: 229-233) 
trucciones de contenido violento por lo que hemos encontrado en nuestra investigación. Todo esto puede crear un clima poco propicio para la paz y la tranquilidad alrededor del mundo de un deporte como es el fútbol.

Además, hay que tener en cuenta que los periodistas son una de las raíces principales de las que parte el vocabulario que se utiliza en el fútbol. Además, "el modo, el estilo y el léxico de quienes producen información son transmitidos por los periodistas e influyen, después, en los destinatarios" (Núñez Ladevéze, 1991: 131). Así, resulta de vital importancia cuidar el léxico por parte de los informadores.

Ante estas actuaciones y conductas de los periodistas deportivos, ante la importancia de los medios de comunicación en esta realidad, se ha solicitado desde varias instituciones como el Senado español, haciendo referencia al Convenio Europeo, aprobado en 1985, que se controle este tipo de lenguaje por parte de los informadores para no influir ni incitar a la violencia en el fútbol ${ }^{8}$.

\section{Metodología}

Para este análisis de los medios de comunicación y su papel de la violencia en el fútbol, nos hemos centrado en los diarios deportivos de tirada nacional que se editan en Madrid, Marca y As. Ambos son el primer y cuarto periódico más leído según el EGM en los últimos registros ${ }^{9}$. Y de estos dos diarios seleccionamos el texto de las crónicas ${ }^{10}$ de los partidos de fútbol de la Liga nacional publicadas los domingos en los dos primeros meses de la temporada 02-03 (septiembre y octubre, porque son los más asépticos, al ser el inicio de la competición, y en el que se esperan menos problemas de violencia). De

\footnotetext{
${ }^{8}$ Señala Ripollés Serrano que "el lenguaje bélico tendente a asimilar el deporte con la guerra, la incitación a veces al chauvinismo e incluso al fanatismo, la representación repetitiva de la violencia que tiende a multiplicarse y a intensificarse con una influencia creciente en la generación de conductas agresivas, el interés económico que privilegia los aspectos morbosos y hace arrancar opiniones provocadoras, la atracción ejercida sobre quienes se mueven por el afán de notoriedad y el exhibicionismo, la obsesión por el recuerdo de incidentes anteriores, son algunos de los eslabones de una cadena que convierte la imagen pública de los espectáculos deportivos en acontecimientos potencialmente violentos. Resulta difícil medir la influencia de los medios de comunicación en el desarrollo de la violencia en el deporte, pero es evidente que el tratamiento de la información deportiva puede limitar o ampliar las causas y los efectos de esa violencia”. (Ripollés, 1990: 215-216)

${ }^{9}$ Según la oleada de octubre de 2005 - mayo de 2006, el Marca tiene 2.418.000 lectores como líder, seguido por El País con 1.970.000, El Mundo con 1.269.000 y el As con 992.000 lectores. www.aimc.es

${ }^{10}$ Como indica Gutiérrez, "mitad narración, mitad valoración de un hecho; regularidad y continuidad; estilo directo y llano; oficio propio del reportero: estas serían, en resumen apresurado, los caracteres fundamentales de la crónica según el profesor Martínez Albertos. La crónica se estructura entre tres bloques: 1. Bloque de titulares: En el que se advierte una fragmentación acusada, con diversos apartados; 2. La llamada "pastilla": En el argot del periodismo deportivo, bloque de datos "objetivos", intento de síntesis documental de lo que ha sido el encuentro (lo que actualmente llamamos "Ficha Técnica”); 3 . Bloque narrativovalorativo: En el que un periodista "analiza" con datos objetivos y subjetivos la noticia esbozada en los titulares". (Gutiérrez, 1991: 31-36)
} 
ahí, estudiamos todos los términos de las crónicas y entresacamos las unidades de texto (palabras, frases, expresiones) que en su contenido o en su contexto tuvieran o mostraran un significado violento. El número de crónicas analizadas ha sido de 44 en total (veintidós por periódico, Marca y As), que son referentes a los mismos partidos de la competición.

Por tanto, el primer paso en el esquema metodológico fue la selección del material. En un principio se escogieron las crónicas de los domingos y los lunes de los primeros cuatro meses de competición (septiembre-diciembre) para finalmente seleccionar los domingos de los dos primeros meses. Además, se analizaban todos los elementos (titular, texto, foto, pie de foto...) que tiene el género elegido, las crónicas de los partidos de fútbol en Primera división en la Liga nacional (la que más seguidores tiene y en la que más problemas de violencia hay). Pero en último caso se acotó la investigación al texto de la crónica.

En segundo lugar seguimos con la clasificación y ordenación del material. Para ello realizamos una serie de fichas técnicas que nos ayudarían a contemplar todo lo relacionado con la violencia que había en la crónica. Esas fichas respondían a la siguiente información: nombre del diario; edición de Madrid con número de periódico y año de publicación; fecha del periódico; número de páginas en total; número de páginas de fútbol; número de páginas de fútbol de Primera división; breve análisis de la portada con especial atención a cuestiones violentas y número de la jornada de Liga y de las crónicas que se analizarían.

A continuación desmenuzamos cada una de las crónicas que se habían publicado ese día según los partidos jugados el día anterior: situación de la crónica en el periódico (número de página) y espacio que ocupaba; estudio de los elementos que venían en la ficha técnica de la crónica; palabras del titular; nombre del redactor o cronista; número de líneas y de palabras del texto de la crónica y si tenía foto y pie de foto que acompañara a la crónica.

Así pasábamos a realizar el análisis concreto de los elementos periodísticos de la crónica: el cuerpo del titular (titular, antetítulo y subtítulo); el texto de la crónica (análisis del lenguaje y de la información que transmitía en un primer momento); la fotografía; el pie de foto y breve análisis del resto de elementos que pudieran hacer referencia a cuestiones violentas.

Desde aquí se partió para seleccionar definitivamente los términos hallados en el texto de la crónica que tuvieran contenido violento. Y para terminar se realizó el pertinente análisis de contenido ${ }^{11}$ de todas

11 “El análisis de contenidos es 'una técnica de investigación que sirve para la descripción objetiva, sistemática y cuantitativa del contenido manifiesto de las comunicaciones de toda clase’. El análisis de contenido presenta... una técnica intermedia... que no desemboca generalmente en un resultado por sí misma, sino que proporciona elementos de juicio que permiten deducir algo en relación con el emisor de un mensaje, o que incluso permiten prever o medir algo en relación con las reacciones del sujeto receptor". Berelson, B. (1952): Content analysis in communication research, Nueva York: Hafner Press. 
las unidades de texto localizadas (el número de unidades de texto de contenido violento localizadas y analizadas ha sido de 253 en el diario Marca y de 338 en el diario As) y se las agrupo por categorías ${ }^{12}$ (grupos semánticos dentro del campo "violencia”, figuras retóricas, expresiones, innovaciones léxicas).

\section{La violencia de los periodistas deportivos a través de su lenguaje en las crónicas de fútbol}

Del periodista se espera, en cualquier género, que sea un intermediario entre cualquier tipo de lenguaje especializado y un lenguaje común, corriente y popular (cotidiano, que lo pueda entender cualquier persona). De ahí la petición de facilitar la información a los receptores. En el lenguaje de los periodistas deportivos, especialmente en el fútbol, los profesionales de la información utilizan un léxico especializado en el deporte y un lenguaje común que procede de la calle, del habla popular ${ }^{13}$. Así, se acercan mucho más los redactores a los lectores, que serán los compradores de periódicos (se mezcla el lenguaje especializado con el cotidiano, y más en un deporte considerado tan popular y propio de todos los estratos sociales, especialmente de los más pobres, como se ha definido en muchas ocasiones al fútbol)

Este lenguaje puede tener un contenido de todo tipo pero es muy habitual encontrarse numerosos términos y frases con significados bélicos y violentos (juegos de palabras, metáforas y figuraciones, palabras procedentes de otros campos semánticos que se aplican aquí por la semejanza de las realidades en las que se emplea...). Además, se puede constatar y comprobar que el lenguaje periodístico, y principalmente el deportivo (como podemos corroborar después de este análisis), está muy influido por el lenguaje literario y con la retórica ${ }^{14}$. Además, la crónica futbolística se presta especialmente a este hecho porque mezcla el lenguaje periodístico y literario, el léxico retórico ${ }^{15} \mathrm{y}$, dentro de este apartado, el que tiene contenido y significado militar, bélico, violento.

12 “Definir cualitativamente las categorías o temas a los que se atribuye suficiente significación como para ser objeto del análisis. Estas categorías vienen determinadas según las necesidades de la investigación, por una parte, pero también están condicionadas por las intuiciones del investigador". Martínez Albertos, J. L., (1995: 140)

${ }^{13}$ Dice Lázaro Carreter a propósito del lenguaje que utilizan los periodistas dentro de lo que denomina "noticia-comentario" que hay una "tercera linde (en el lenguaje de los periodistas en este género, aparte del literario y el administrativo), aquélla que el idioma periodístico comparte con el idioma que no sé si llamar popular o vulgar, y que tal vez convenga denominar, más asépticamente, lenguaje de base oral. A simple vista, parece muy sugestiva la idea de que un modo de aproximación al lector consiste en imitar o usar confianzudamente el estándar hablado. De esa manera, se piensa, quedan superadas las diferencias culturales, se llega a más público, y el hecho comunicativo alcanza mayor intensidad". Y más adelante apunta que "contra lo que me permito prevenir es contra una coloquialización abundante y extemporánea de la noticia”. Lázaro Carreter, F. (1977: 26-31)

14 "La relación que más se ha hecho notar ha sido la del lenguaje deportivo con el lenguaje literario y con la retórica. Dentro de este planteamiento encuentran explicación apropiada características tan definitorias del lenguaje deportivo como la tendencia a la innovación expresiva o los rasgos coincidentes con lo épico que se observan en las crónicas deportivas". Lázaro Carreter, F. y otros (1992: 13-14)

${ }^{15}$ El profesor Gutiérrez señala que "dos son las principales razones que impelen al cronista deportivo a efectuar un uso literario del lenguaje: la intención de embellecer el drama, en palabras de Vicente Verdú, y la de remover el ánimo de los lectores exacerbando la pasión por el espectáculo. Es un partido, en la mayoría de los casos, un conjunto de acciones reiterativas muy 
Por tanto, partimos de la base, en este análisis de contenido, de palabras y oraciones ${ }^{16}$ que nos encontramos en un contexto muy identificado, concreto. Y son palabras y oraciones que en su sentido comunicativo transmiten un significado violento (sería el campo semántico "violencia" como clasificador general de las unidades de significación).

La definición de "léxico violento" que aportamos responde a lo siguiente: "Lenguaje que tiene por significado o contenido semántico una realidad violenta o agresiva y transmite una acción así, ya sea con el término en su acepción natural contemplada en el DRAE o por la metáfora utilizada por el cronista desde los distintos campos semánticos que representan una acción violenta, en concreto el ámbito bélico y militar. También se han contemplado los términos deportivos o bélicos adaptados al deporte y las palabras del lenguaje futbolístico que hacen referencia a una acción violenta dentro del juego (que hemos clasificado como términos punitivos) o las expresiones que pueden ser despectivas utilizadas por los cronistas deportivos. Por último, se han tenido en cuenta las frases o términos que pudieran conllevar una realidad polémica y que así pudiera desencadenar una reacción violenta”.

Las categorías para el análisis de contenido son "secciones o clases que reúnen un grupo de elementos bajo un título genérico, reunión efectuada en razón de los caracteres comunes de estos elementos” (Bardin 1986: 90). Y estas son las que hemos encontrado:

- Categoría 1: "Término con contenido violento". Son los términos y frases que contienen un significado violento en alguna de sus acepciones contempladas por el DRAE. Los términos pueden conllevar o no una acción violenta dentro de la semántica que transmiten. En el diario Marca encontramos unidades como "puntería", "amordazaron", “choque", "el Depor vio peligrar un poco el partido", "sin capacidad de pegada" o "luchando con tipos de verdad". Y del diario As tenemos palabras y oraciones como "tarascada", "patadón”, “amenazó”, "se estrelló”, “en la primera jugada, sacó el hacha y sin contemplaciones se fue directo a por el canario, que tuvo que abandonar el campo cojeando" o "el Osasuna fue víctima".

\footnotetext{
limitadas por el reglamento. Otras veces deviene en un espectáculo decididamente vulgar. La crónica procura siempre sacarlo de la vulgaridad; el periodista escarba en lo profundo de su ingenio y usa de los recursos "embellecedores" del idioma para que lo que ha visto alcance esplendor (...) La crónica, en especial la de los periódicos exclusivamente deportivos, cumple una función de sintonía con las opiniones de los lectores, y también una función perlocucionaria: la pasión deportiva encuentra en la crónica signos para la excitación, para la emoción (...) Se percibe que el lenguaje está condicionado por una especie de impulso épico (...) El uso de muchos términos del área de la milicia contribuía a dotar al discurso de una cierta epicidad (...) Para la construcción de la epicidad y el fomento de la emoción, los periodistas deportivos suelen echar mano de los recursos más conocidos estudiados por la retórica clásica. La que fue técnica para ejercitar la persuasión en los discursos oratorios se constituye en un conjunto de figuras y tropos que también contiene normas para el embellecimiento y la exaltación del sentimiento”. Gutiérrez, D. (1991: 311-313).

16 "Una oración es una unidad de significado predicativo que puede funcionar como unidad sintáctica comunicable independientemente del contexto" que además conocemos en este estudio al tratarse de lenguaje futbolístico empleado por los periodistas en sus crónicas. Núñez Ladevéze, L. (1993: 41)
} 
- Categoría 2: "Término bélico y militar". Esta categoría hace referencia a los términos y frases que entre sus acepciones el DRAE contempla un significado propio del campo semántico bélico y militar. Así, en el diario Marca tenemos “cercar”, “consignas”, "pugnaron”, “...Figo, Zidane y Raúl permutaban posiciones en busca de espacios entre las ordenadas líneas béticas”, "Tiko y compañía dominaban casi toda la geografía del campo" o "poco a poco, como un acto reflejo, los de Jabo fueron retrocediendo". Y en el diario As, unidades como "incursiones", "acción aislada", "marcha militar", "presionar", "misión imposible” o "pelear sin rendición”.

- Categoría 3: "Término bélico y militar adaptado". En esta ocasión la diferencia con la categoría anterior es que los términos usados por los periodistas deportivos estén totalmente asentados en el lenguaje futbolístico aunque haya que reconocer su procedencia del léxico bélico y militar. Son términos adaptados en el campo semántico deportivo y más concretamente en el futbolístico. Por ejemplo, en el diario Marca tenemos "disparo", “capitán”, “tiro”, “defensa”, "remate”, "las bajas de Fernando, Luis García y Tote" o "en la reserva”. Y en el diario As, "mucha estrategia”, "victoria", "ataque”, "puntas" (delanteros, atacantes, los jugadores más adelantados), "el Depor se repobló en el mediocampo", "aunque enfrente tuvo un adversario que es muy duro de pelar" o "mejores piezas ofensivas".

- Categoría 4: “Términos que hacen referencia a agresiones de unos contra otros". Esta categoría engloba a los términos y frases que reflejan acciones violentas y agresiones de los protagonistas que participan en el encuentro futbolístico. Algunos de los ejemplos en el diario Marca son "falta", "realizó una dura entrada que le costó la roja", "los navarros, a veces con excesiva brusquedad, sumieron al Depor en un pozo de desconfianza y temor", "sacó a Peña para frenar a Valerón", "Peña, antes de tocar el balón, hizo una entrada por detrás escalofriante que dio con los huesos de Valerón en el vestuario” o "el Depor se dedicó más a vengar la agresión a su compañero que a jugar al fútbol". Y en el diario As tenemos frases como "Vicente agarra al Mono", "metió la pierna" (ir a por el jugador contrario con una acción violenta), "ni un buen gesto pero sí muchas feas acciones" (agresiones, aunque fueran durante el juego), "Figo sufría una y mil caídas de impotencia" (le hacían faltas), "que expulse a Salgado en un minuto caliente" o "sorteó una entrada playera de Helguera” (acción violenta durante el juego).

- Categoría 5: “Términos usados como sinónimo bélico". Se define por las palabras o frases que se utilizan en el lenguaje futbolístico propias del campo semántico bélico y militar y se aplican como sinónimo en el léxico del fútbol. La semejanza del enfrentamiento en la guerra y en el fútbol hace que se tomen palabras de otros campos semánticos y los cronistas deportivos lo utilizan para no repetir los mismos términos. A la hora de seleccionar sinónimos, se toman en muchas ocasiones del lenguaje bélico y militar. Así, en el diario Marca hemos localizado unidades como "mordiendo" (que el equipo estaba atacando), "duelo" (partido), "por los dos bandos” (los dos equipos), "za- 
patazo de Nagore" (tiro, disparo), "latigazo a la red" (tiro, disparo) o "golpes francos" (disparo, lanzamiento). Y en el diario As: "estacazo" (derrota difícil de aceptar), "palizón” (victoria por goleada), "trallazo de Ayala" (tiro), "revienta la red" (marca gol), “quien aspira a arrasar” (ganar) o "ahogaba las intentonas madrileñas" (los ataques).

- Categoría 6: “Términos punitivos”. Son las palabras que representan una acción sancionable por parte del juez del campo, el árbitro. En este caso, los "términos punitivos" son los que hacen referencia a acciones violentas por parte de los jugadores y que los periodistas utilizan principalmente para informar de lo que ocurrió durante el encuentro de fútbol. En el diario Marca tenemos "penalti", "absurda y evitable expulsión de Salgado" o "Salas se dejó caer y el árbitro señaló penalti”. Y en el diario As: "pena máxima” (penalti), "se quedaron con diez muy pronto” (hubo una expulsión) o "roja a Luís Fernández... roja a Filipescu” (dos jugadores expulsados por acciones violentas, ilegales) Son palabras que también hacen mención a una acción violenta, en esta ocasión dentro del propio desarrollo del juego. La acción conlleva lógicamente una pena o sanción por conducta antirreglamentaria.

- Categoría 7: “Expresiones despectivas usadas metafóricamente”. Dentro de esta categoría hemos englobado las expresiones despectivas que realiza el cronista deportivo en su crónica hacia algún protagonista del partido de fútbol sobre el que está informando. Estos términos también tienen contenido violento y salen directamente de la opinión crítica del periodista en su análisis de lo sucedido en el encuentro. En este caso hemos encontrado expresiones especialmente en el diario As como "todo lo que se le ocurrió a Cabeza de ladrillo" (el cronista llama así, "Cabeza de ladrillo", al entrenador de un equipo porque le representaban de esta forma en un programa de humor en televisión), "anatomía... de una violación, la de Van Gaal” (con lo que el cronista quiere representar metafóricamente que un equipo ganó al contrario y así "violó" a su entrenador), "los que parecen una banda" (define a un equipo como "una banda callejera" y tiene connotaciones insultantes), "chapuza" o "encontró la clave engañando a la mente más plana que había sobre el césped: al mal árbitro Téllez Sánchez”. El termino "lamentable”, que utiliza para hablar de la falta de organización de un club (en sentido despectivo hacia la entidad), es el único que hemos encontrado en el diario Marca.

- Categoría 8: "Metáfora con contenido violento". Se define por las expresiones metafóricas ${ }^{17}$ que tienen contenido violento y que muy a menudo utilizan los cronistas para representar una idea o

\footnotetext{
${ }^{17}$ Lakoff y Johnson sostienen en su estudio sobre las metáforas en la vida cotidiana que "la metáfora no es solamente una cuestión del lenguaje, es decir, de palabras meramente. Sostenemos que, por el contrario, los procesos del pensamiento humano son en gran medida metafóricos... El sistema conceptual humano está estructurado y se define de una manera metafórica”. Lakoff, G. y Johnson M. (1998: 42)
} 
lance del juego. En este apartado hemos clasificado términos o frases en el diario Marca como "cazó”, "peleó”, "garra”, "peligro”, “y ajustició a Lafuente”, "salir a tumba abierta”, "metiendo al rival en cintura" o "el canario descosió a su rival”. Y en el diario As: "De lo contrario algún jugador blanco... aparece y te clava el puñal”, “el Depor llegaba sangrando a Vallecas y necesitaba un torniquete para que no se le fuera la vida", "al Barça le habían roto el himen y el plan", "el Barça, tan roto y violado como la libreta de Van Gaal, había hecho el ridículo", "el que lo asesinó fue el Betis", "la bestia blanca despertó y dio dos coletazos de suficiencia letales", "Alfonso ejecutaba al Barça", "tiene un plus mortal" o "la rapidez y precisión de Makaay mató a Osasuna".

- Categoría 9: "Metáfora con contenido bélico y militar". En este apartado hemos clasificado las expresiones metafóricas que tienen su raíz en el campo semántico bélico y militar. Multitud de ejemplos se podrían clasificar en la categoría anterior de "metáforas con contenido violento", que en muchas ocasiones también es propiamente así, pero aquí hemos englobado las frases y términos que salen directamente y tienen más relación con el lenguaje bélico y militar. Algunos de los casos que hemos encontrado en el diario Marca son "tranquilidad para armar la zurda", "Kluivert tenía la escopeta cargada", "perdieron la crucial batalla", "zonas vetadas", "contener" o "balones aéreos". Y en el diario As: "Se lanzó con toda su artillería”, "el Depor se atrincheró", "acabaron respirando por diez heridas abiertas en todas las líneas", "comenzó la guerra”, "bloque de guerrilleros", "pelearon con todas sus armas sin gestos quejicosos", "sobreviviría como podía a los ataques amarillos", "la torre de Carew en ataque" o "con punta de lanza en el escurridizo Rosado".

- Categoría 10: “Críticas hacia algún protagonista”. Se define por las frases y términos que realiza el cronista deportivo con contenido crítico hacia algún protagonista del encuentro. Estas críticas le apuntan como culpable de lo sucedido sobre el terreno de juego y puede provocar reacciones violentas por parte de otros personajes. Además, en algunas ocasiones estos comentarios por parte del periodista tienen connotaciones que faltan al respeto a los protagonistas de los que se habla. También hemos incluido en este apartado las frases que de forma intrínseca transmiten una crítica. Entre los ejemplos encontrados en el diario Marca están "la estrella estrellada fue Turienzo", "el siguiente paso era: o le expulsaba un jugador al Recre, o le birlaba un penalti. Esto último fue lo que pasó... Encima de malo, compensando", "y Pérez Burrul, tan campante, fue cómplice de la agresión al sacarle sólo amarilla en una entrada flagrante por detrás y sin balón”, "Losantos no vio penalti. Vio pañuelos", "dos penaltis inexistentes" o "Salgado... terminó perjudicando a su equipo" (de estas seis unidades de texto, las cinco primeras hacen referencia al árbitro y la última a un futbolista). Y en el diario As: "Cansa la crónica, pero juro que es culpa del árbitro, de Turienzo", "conteste, por qué De Boer y Cocu pueden dar esas patadas y acabar los partidos", "la resistencia madridista era un saco de bombas y se encargó de que explotara el despistado árbitro”, "Ramírez Domínguez se cargó el partido con doble amarilla simultánea a Salgado”, "Se- 
ñor Megía: ¿patear a Tamudo está permitido por el reglamento?", "Turienzo montó un circo de los grandes", "López Nieto se comió un penalti", "Ramírez Domínguez pitó horrible, indignante" o "Moreno Delgado había perjudicado a los visitantes [...], decidió llevar hasta última instancia la ley de la compensación e ignoró el penalti” (en este caso, el balance del diario As en general es que sus críticas se dirigen especialmente hacia los colegiados como comprobamos aquí)

- Categoría 11: "Búsqueda de polémica”. Es muy habitual ver cuestiones polémicas en las páginas de los diarios deportivos. Dentro de esta clasificación hemos constatado que en este género periodístico también se encuentran frases que transmiten la búsqueda de la polémica por parte de los periodistas. Aun así, en las crónicas sólo se hace mención a este tipo de realidades cuando se trata de algo especialmente importante (goles de un jugador contra un ex equipo, crisis de los equipos, que se pierda ante un rival a priori de menor categoría, etc.). Así, entre los ejemplos en este análisis en el diario Marca sólo hemos encontrado la unidad de texto "un foco de morbo" que hace referencia a un entrenador que podía ser destituido por los malos resultados de su equipo. Y en el diario As tenemos "Munitis lo celebró rabioso y sin camiseta, justiciero, vengándose del equipo que le paga... pero que no supo apreciar su talento", "llegó la afrenta que faltaba" o "crisis entera" (hace mención a una mala situación que atraviesa un equipo en la competición).

- Categoría 12: "Innovaciones léxicas-Neologismos". En esta última categoría que hemos denominado así, englobamos los términos o frases que inventan los periodistas deportivos en sus crónicas para representar alguna idea particular sobre el desarrollo del juego ${ }^{18}$. En muchas ocasiones tienen su raíz en juegos de palabras. Esto es algo muy habitual en el lenguaje de los periodistas deportivos. En el diario Marca no se ha localizado ningún término de esta categoría pero en el diario As tenemos estos casos: "vangalismo salvaje" que hace referencia al entrenador de un equipo llamado Van Gaal (el cronista utiliza esta frase para definir sus decisiones y lo hace con un juego de palabras: de "Van Gaal" sale "vangalismo") y "tanta madriditis va a condicionar malamente a los árbitros" ("madriditis" es una palabra inventada para señalar que los que no son seguidores del equipo Real Madrid les odian; el sufijo "-itis" procede del campo semántico médico y que significa "inflamación" en términos como "otitis" o "hepatitis"; por tanto, el cronista quiere decir que hay "inflamación Real Madrid” en los seguidores rivales del equipo madridista)

${ }^{18}$ Ya lo señala Castañón, que "uno de los aspectos más destacados en la lengua especial del periodismo sobre fútbol está compuesto por la presencia de neologismos". Además, dice que "en la formación de las anomalías semánticas han intervenido causas psicológicas, como la búsqueda de expresividad; históricas, en relación con la evolución del fútbol y sus estamentos; sociales, como la extensión de un sentido por su generalización o por su restricción de sentido dentro de la lengua especial; y lingüísticas, como el afán de innovación lingüística y de creación de nuevos códigos expresivos”. Castañón, J. (1993: 27-28) 


\section{Conclusiones}

En primer lugar, hay destacar el aspecto "agonístico" inherente a la práctica deportiva donde la diferencia con la violencia es la raíz del enfrentamiento deportivo. Aun así, desde las instituciones deportivas se recomienda que los protagonistas del deporte cuiden todas sus conductas, declaraciones y actitudes no solo en los eventos deportivos sino también en su vida privada por la influencia que puedan tener en los seguidores del deporte ${ }^{19}$. Y es que se puede entender que el lenguaje también posea cierto aspecto agonístico. Por tanto, los periodistas deben atender igual a esa recomendación de valorar la repercusión en otras personas que pueden tener sus comentarios, expresiones, informaciones, etc.

Son muy habituales en el lenguaje de los periodistas deportivos, principalmente en sus crónicas, las expresiones metafóricas bélicas, al igual que las figuraciones con contenido violento en general. Buena parte del léxico empleado en el lenguaje de los cronistas deportivos nace o se emplea procedente del bélico y militar. Esta es una de las principales conclusiones que hemos sacado en este estudio. Las metáforas violentas, bélicas y militares provocan que se pueda crear un ambiente igual en el mundo del deporte, y del fútbol en particular ${ }^{20}$. Y en este sentido podríamos decir que el lenguaje y las expresiones léxicas utilizadas por los periodistas deportivos determinan la concepción que tengamos de los encuentros de fútbol, según la metáfora "un partido de fútbol es una batalla o una guerra" (Lakoff y Johnson, 1998: 117)

Con este estudio hemos comprobado que desde los periódicos deportivos se intenta trasladar al lector la espectacularidad del deporte. Así, el diario deportivo se convierte también en un espectáculo, e incluso dentro de los textos periodísticos, y especialmente en el ámbito de las crónicas, se introduce la "emoción" propia del juego con el estilo informativo-literario de los redactores.

Se puede aceptar que el periodista utilice metáforas literarias, por un lado con un efecto identificador de su estilo, y por otro lado, con el objetivo de ofrecer un texto más atractivo y original. Pero también sería recomendable que las figuraciones no encerraran el contenido violento y bélico que hemos encontrado en este análisis, sobre todo para referirse a hechos simples como por ejemplo, para señalar que se ha marcado un gol, representarlo con la metáfora "aparece y te clava el puñal", que hemos leído en

19 “Deben valorar también la posible repercusión que en otras personas tengan sus manifestaciones, actitudes, etc., no sólo en el ámbito de la xenofobia sino también en el de la violencia, tan sensibles ambas por ese aspecto agonístico de la práctica deportiva" ha señalado, por ejemplo, el Comité de Competición de la Real Federación Española de Fútbol, referente a alguno de sus casos (Resolución del 1 de marzo de 2005, caso Luis Aragonés)

${ }_{20}$ "La prensa escrita, así como la radiofónica, se ha referido siempre superfluamente a dicho fenómeno (violencia en el fútbol), empleando con reiteración un lenguaje bélico, que en el fútbol se visualiza en diversas metáforas constantes (identificación guerra $=$ = fútbol, batalla = partido) utilizando un código propio de guerra que puede llegar a incitar el uso de la violencia. Tanto la prensa como los staff técnicos de los clubes han utilizado paralelismos entre los términos bélicos y los futbolísticos (ataque, contraataque, lucha, escuadra, partido a muerte, al enemigo ni agua...)" Viñas, C. (2005: 158) 
las crónicas del diario As. Consideramos que se puede mantener el componente retórico, literario y particular de la obra sin que sea necesario utilizar este tipo de figuraciones.

Otro aspecto destacable de las crónicas futbolísticas es su componente retórico y las consecuencias ("efectos secundarios") que puedan acarrear en los receptores (como lenguaje público y además como lenguaje retórico $\left.{ }^{21}\right)$. Es decir, los textos retóricos pueden llamar más la atención y también tienen la misión de llegar más lejos e incluso "caldear" a los lectores. Ese efecto puede representarse en los receptores con cualquier tipo de acción, por ejemplo, violenta.

Además, no se puede olvidar que las metáforas de contenido violento y bélico, el léxico violento, puede acabar calando en el lenguaje común del deporte no sólo entre los periodistas sino también entre los aficionados y los demás protagonistas del mundo del fútbol. Los informadores son propagadores y creadores de lenguaje, de estilos léxicos. Además, las metáforas conllevan un juego de palabras que puede resultar muy atractivo para el receptor de los medios de comunicación. Por este motivo, es más fácil que se instalen en el lenguaje popular y común incluso las figuraciones que posean contenido violento.

Así, los efectos del lenguaje, la forma de escribir, el estilo, la retórica y los hechos destacados en una crónica pueden dirigir las acciones, los sentimientos o las intenciones de los lectores. En este análisis no hemos estudiado los efectos que pueden provocar los términos, las metáforas, las críticas, las expresiones despectivas, las polémicas, las referencias a actos violentos, pero sí sostenemos que contribuyen a crear un clima propicio para la aparición de actos violentos. Esto también puede constituir una de las causas de la violencia en el fútbol (de ahí que se recomendara desde todas las altas instituciones como el Senado español haciendo mención al Convenio Europeo de 1985)

Hay que reconocer que el lenguaje de fútbol tiene muchos términos que son difícilmente sustituibles por otros con menos contenido o connotación violenta o bélica. Palabras como "tiro" o "disparo" se han asentado en este léxico deportivo y se han convertido prácticamente en imprescindibles a la hora de narrar lo que sucedió en el terreno de juego.

Hemos podido encontrar y constatar así que el lenguaje que utilizan los cronistas no siempre es educado. Hemos hallado expresiones despectivas hacia alguno de los protagonistas del fútbol. Estas frases pueden herir su sensibilidad (violencia psicológica que puede repercutir en física o técnica por parte del protagonista) y provocar la falta de respeto por parte del resto de personajes. Además, con frecuencia se trata de buscar la polémica, o hacer referencia a ella, en todas las acciones que se producen dentro del terreno de juego.

21 "La retórica es el arte del bien decir. Las retóricas son los excesos lingüísticos para refocilarse con lo dicho, para caldear también al que lee o escucha... el lenguaje público causa también efectos secundarios”. De Miguel, A. (1985: 157) 
Contemplamos en este estudio la subjetividad del periodismo al comprobar que cada periodista concibe la realidad de una forma y le concede más importancia a unos aspectos que a otros. Recordemos que este estudio recoge las crónicas de los mismos partidos procedentes de dos periódicos diferentes, los diarios deportivos Marca y As. El cronista puede destacar lo que considere más importante, pero hemos constatado que no coinciden en los hechos puesto que, por ejemplo, en el diario As se dedican más críticas a los protagonistas que en el diario Marca, especialmente hacia el árbitro.

Por último, hemos comprobado que el léxico empleado es muy similar dentro del periodismo deportivo. En este caso lo hemos comprobado al comparar el lenguaje que utilizan Marca y As, dos de los diarios deportivos más leídos del país. Hay términos que se consideran básicos en el deporte (por ejemplo, "defensa") pero las figuraciones y expresiones empleadas son creación particular del redactor ("Kluiver tenía la escopeta cargada"). Por tanto, podemos concluir que están a la par ambos diarios a la hora de escribir con imágenes, metáforas y términos de fondo bélico y violento. El lenguaje se instala en el entorno de esta realidad y todos los protagonistas y medios de comunicación acaban utilizando el mismo léxico.

\section{Referencias bibliográficas}

- Agulló, R. (2003): Diccionario de términos deportivos, Madrid: Espasa.

- Alcoba, A. (1987): Deporte y comunicación, Madrid: Dirección General de Deportes de la C.A.M.

- Bandura, A. (1987): Pensamiento y acción, Madrid: Martínez Roca.

- Bandura, A. (1987a): Teoría del aprendizaje social, Madrid: Espasa Calpe.

- Bardin, L. (1986): Análisis de contenido, Madrid: Akal.

- Berelson, B. (1952): Content análisis in communication research, Nueva York: Hafner Press.

- Cagigal, J. M. (1990): Deporte y agresión, Madrid: Alianza.

- Casasús, J. M. y Núñez Ladevéze, L. (1991): Estilo y géneros periodísticos, Barcelona: Ariel.

- Castañón, J. (1993): El lenguaje periodístico del fútbol, Valladolid: Secretariado de publicaciones, Universidad de Valladolid.

- Castañón, J. (2004): Diccionario terminológico del deporte, Gijón: Trea.

- Clemente, M. y Vidal, M.A. (1996): Violencia y televisión. Madrid: Noesis, 1996.

- Coca, S. (1993): El hombre deportivo, Madrid: Alianza Deporte.

- De Antón, J. y Pascual del Riquelme y Tejera, A. (1990): Factores que promueven la violencia en el deporte con especial referencia al fútbol, Madrid: Consejo Superior de Deportes, Dirección General de la Policía y RFEF. 
- De Miguel, A. (1985): La perversión del lenguaje, Madrid: Espasa Calpe.

- Dijk, T. Van (1990): La noticia como discurso, Barcelona: Paidós.

- Durán, J. (1996): El vandalismo en el fútbol, Madrid: Gimnos.

- Durantes, C. (1984): Agresividad, violencia social y deporte, Madrid: Academia Olímpica Española.

- Elias, N. y Dunning, E. (1992): Deporte y ocio en el proceso de civilización, Madrid: Fondo de cultura económica.

- Fagoaga, C. (1999): La violencia en medios de comunicación: Maltrato en la pareja y agresión sexuada, Madrid: Dirección General de la Mujer. Consejería de Servicios Sociales.

- FIFA (Federación Internacional de Fútbol): www.fifa.com (3/Abril/2001). Agencia EFE: Teletipo (entrada 3/Abril/2001). Diario Marca, Madrid, 4/abril/2001 (p. 36).

- Gutiérrez, D. (1991): Estructura y lenguaje de la crónica de fútbol, Madrid: Universidad Complutense de Madrid.

- Imbert, G. (1992): Los escenarios de la violencia. Conductas anómicas y orden social en la España actual, Barcelona: Icaria Editorial.

- Klapper, J.T. (1974): Efectos de las comunicaciones de masas, Madrid: Aguilar.

- Lakoff, G. Y Johnson, M. (1998): Metáforas de la vida cotidiana, Madrid: Cátedra.

- Lázaro Carreter, F. (1977): “El lenguaje periodístico, entre el literario, el administrativo y el vulgar”, en Lázaro Carreter, F. y otros: Lenguaje en periodismo escrito. Madrid: Fundación Juan March, pp. 26-31.

- Lázaro Carreter, F. y otros (1992): El idioma español en el deporte, La Rioja: Gobierno de La Rioja y Agencia EFE.

- Le Guern, M. (1976): La metáfora y la metonimia, Madrid: Cátedra.

- Martínez Albertos, J. L. (1995): Curso General de Redacción Periodística, Madrid: Paraninfos.

• Núñez Ladevéze, L. (1979): El lenguaje de los “media”, Madrid: Pirámide.

- Núñez Ladevéze, L. (1991): Manual para periodismo, Barcelona: Ariel.

- Núñez Ladevéze, L. (1993): Teoría y práctica de la construcción del texto, Barcelona: Ariel.

- Núñez Ladevéze, L. (1993): Métodos de redacción periodística y fundamentos de estilo, Madrid: Síntesis.

- Ripollés Serrano, R. M. (1990): Dictamen de la comisión especial de investigación de la violencia en espectáculos deportivos, con especial referencia al fútbol. Senado Español. 
- Rojas Marcos, L. (1995): Las semillas de la violencia, Madrid: Espasa Calpe.

- Sanmartín, J. (2000): La violencia y sus claves, Barcelona: Ariel.

- Seijas, L. (1988): La violencia en televisión, Madrid: U. Complutense.

- Viñas, C. (2005): El mundo ultra. Los radicales del fútbol español, Madrid: Temas de hoy.

- www.aimc.es (EGM)

- www.ojd.es 
